\title{
Practical considerations in the delivery of genetic counseling and testing services for inherited cancer predisposition
}

\author{
Tuya Pal, MD, ${ }^{1}$ Cristi Radford, MS, CGC, ${ }^{1}$ Susan Vadaparampil, $\mathrm{PhD}, \mathrm{MPH},{ }^{2}$ and \\ Anya Prince, BA, JD, MPP 3
}

Departments of ${ }^{1}$ Cancer Epidemiology and ${ }^{2}$ Health Outcomes and Behavior, Moffitt Cancer Center, Tampa, Florida; ${ }^{3}$ Cancer Legal Resource Center, Disability Rights Legal Center, Los Angeles

\begin{abstract}
Many professional entities endorse the need to deliver cancer genetics risk assessment (CGRA) services through a multidisciplinary team that includes trained genetics professionals. However, market forces, a lack of regulation of genetic testing, patent laws, cost barriers, and a limited workforce in genetics have resulted in an increasing number of community practitioners who order and interpret genetic testing. In addition, varying state-level laws and licensure requirements for genetic counselors may contribute to the nonuniform delivery of CGRA services across the United States. Those who perform genetic testing without having adequate training or expertise may incur liability risks. Moreover, the patient might not enjoy the maximum benefit of testing at the hands of an inadequately trained individual. In the setting of a limited number of professional who are trained in CGRA and a dearth of education and training resources, it is a challenge to integrate genetic testing services into clinical care. With advances in genomics and the implementation of personalized medicine, the problem will only be magnified, and it is critical that there are more opportunities for high quality education and training in clinical cancer genetics free of commercial bias. Successful strategies for delivering comprehensive CGRA services include academic-community partnerships that focus on collaboration with nongenetics providers or the inclusion of a genetics professional in the community setting as part of multidisciplinary patient care. These approaches can leverage the expertise of genetics professionals while allowing patients to remain in their community and enjoy better access to resources for long-term follow-up care.
\end{abstract}

0 everal professional organizations have published guidelines that illustrate the complexities of delivering high-quality CGRA services and the need for the involvement of trained genetics professionals. ${ }^{1-10}$ There are 3 main groups of health care professionals with advanced degrees and experience in genetics: certified genetic counselors (CGC), who have at least a Master's degree in genetic counseling and have passed a national board examination; diplomates, American Board of Medical Genetics (DABMG) or fellows, American College of Medical Genetics (FACMG), who are physicians who have completed residency or fellowship training in medical genetics and who have passed the board examination; and advanced practice nurses in genetics (APNG), who have completed a graduate nursing program and a professional portfolio review process. The traditional model for delivering these services begins with an

\footnotetext{
Manuscript received July 6, 2012; accepted November 9, 2012. Correspondence Tuya Pal, MD, Moffitt Cancer Center, 12902 Magnolia Drive, Tampa, FL 33612 (tuya.pal@ moffitt.org).

Disclosures None of the authors has any disclosures.
}

in-person pretest genetic counseling session followed by a results disclosure session ${ }^{1}$ and is conducted by a certified or credentialed genetics professional $^{2}$ who has been trained to provide a detailed risk assessment that would include a differential diagnosis, education, and medical management options for hereditary cancer. ${ }^{3-6}$ In the tertiary care setting, CGRA services are increasingly delivered by a multidisciplinary team that includes genetic counselors who work with oncologists, medical geneticists, other medical specialists, and often a mental health professional. ${ }^{7}$ Thus, it is important to appreciate the multidisciplinary nature of the provision of these services, which requires knowledge of genetics, oncology, and patient and family counseling skills.

\section{Factors that influence delivery of CGRA services}

\section{Market forces}

Despite efforts to expand community-based best practices for the provision of genetic counseling 
and testing services, market forces compel an increasing number of clinicians with limited training or experience in CGRA to order and interpret genetic tests. ${ }^{8-13}$ Of particular concern are commercial laboratories that directly target community-based physicians. ${ }^{13,14}$ These types of marketing strategies for a test that is not indicated for most of the population leads to limited patient benefit, while increasing the volume of tests performed by the testing laboratory. ${ }^{15,16}$ Consequently, as policy makers formulate the regulation of this growing industry, it is critical to consider the content and framing of risk information through these direct-to-consumer (DTC) marketing campaigns. There has been little regulation at the federal and state level of DTC marketing for genetic tests. Currently, 13 states prohibit DTC marketing outright, and 26 states, including the District of Columbia, permit it without restrictions. ${ }^{14}$ This variation in regulation from state to state can greatly affect families across the nation as each family may have different access to interpretations by medical professionals depending on which state they live in.

\section{Lack of regulation}

Organizations that have authority to regulate genetic testing include the Food and Drug Administration (FDA) and the Centers for Medicare and Medicaid Services through the Clinical Laboratory Improvement Amendments (CLIA). ${ }^{15,16} \mathrm{~A}$ genetic test may be developed as a "test kit" or a "home brew." Test kits are prepackaged with reagents and instructions and sold to laboratories, whereas home brews are assembled in-house by the laboratory. Test kits are regulated by the FDA as medical devices, thus manufacturers must submit data on analytic and clinical validity and utility to the agency for approval before it can be marketed. The FDA has approved 4 test kits to detect mutations in human DNA, of the hundreds of diseases for which genetic tests are currently available clinically. ${ }^{15}$ In contrast, home brews are under CLIA oversight, which requires laboratories to perform proficiency testing to demonstrate their ability to accurately perform the test and interpret the results- but they do not need to demonstrate clinical validity or utility. Thus, under CLIA, the decision to offer a new genetic test is within the sole discretion of each clinical laboratory director. As a result, most genetic testing is currently overseen by CLIA rather than the FDA, which suggests that manufacturers prefer the less-regulated status and that the regulatory regime allows them to avoid stringent FDA oversight. Ultimately, there are clear opportunities to develop a regulatory system to ensure that patients and providers receive greater assurance that genetic tests are accurate and reliable and provide information that they are relevant to health care decision making. Currently, mutation detection strategies and detection rates for a given gene may vary by testing laboratory because of the techniques that are used, so the patient's mutation may be detected by one laboratory but not another. Consequently, practitioners who provide genetic testing services require familiarity with laboratory testing approaches, as patients rely on them to research and select the laboratory best suited for their genetic needs.

\section{Patent laws}

Patent laws in the United States may also limit the amount of genetic testing interpreted by those fully trained in CGRA. About 20\% of human genes are patented. ${ }^{17}$ This means that the owner of the patent has the exclusive right to study, test for, and look at a gene and can preclude others in the country from using the gene for those purposes. One example is the patent for the $B R C A$ genes, which gives Myriad Genetics, the patent holder of the BRCA genes, the sole rights to perform clinical $B R C A$ testing within the United States. There are suggestions that patents may limit access to affordable testing, especially in instances in which patent rights holders prevent other laboratories from offering the test or do not accept requests from some insurers or insurance programs. ${ }^{18,19}$ The issue as to whether genes can be patented has received much attention because of a lawsuit whose arguments were heard in the Supreme Court of the United States in April 2013. The lawsuit had been brought against Myriad Genetics in 2009 in the Federal District Court, Southern District of New York. The Association of Molecular Pathology (AMP) et al. vs US Patent and Trademark Office was joined by the American Civil Liberties Union (ACLU), the Public Patent Foundation, patient advocacy groups, and the academic research community, all of whom have different interests in policies relating to gene patenting. The lawsuit argued that the monopoly that was created through the patent on the $B R C A$ genes stifled research and limited women's options regarding their medical care. In 2010, Judge Robert Sweet ruled that the patents were invalid because DNA is a product of nature and they were therefore not patentable. However, that ruling was mostly overturned on appeal in summer 2011 by the US Court of Appeals for the Federal Circuit, which decided that some DNA, such as cDNA molecules, could be patented because they were not found in nature. However, given Myriad's broadest method, claim patents were invalid because they referred to a mental act, a way of comparing sequences to look for differences, which cannot be patented. Subsequently, the Office of the Solicitor General in the Department of Justice filed a brief siding with the plaintiffs 
and against Myriad. On February 17, 2012, the Supreme Court of the United States began considering whether to take up the case, however in March the court decided to bounce the case back to the lower court because of the Prometheus ruling. In this case, which involved patents related to the proper drug dosing of certain drugs for autoimmune diseases by correlation with blood biomarkers, the Supreme Court said the patents were invalid because they describe laws of nature. In June 2012, the ACLU and Public Patent Foundation filed a brief with the US Court of Appeals for the Federal Circuit to continue the case at the lower level, which once again upheld the patents (in August 2012). The ACLU filed a petition with the Supreme Court on September 24, 2012, to which the Supreme Court agreed to hear arguments (in November 2012). On April 15, 2013, the ACLU argued before the Supreme Court that patents on BRCA1 and $B R C A 2$ are invalid, the outcome of which is eagerly anticipated in June 2013.

Ultimately, as patents and claims interfere with the great advances in sequencing technologies that have made whole-genome and whole-exome sequencing practical, it is expected to become increasingly unfeasible to apply for licenses or collect royalties. ${ }^{18}$ In fact, some laboratories within the United States that currently perform this type of testing blind the $B R C A 1$ and $B R C A 2$ sequences from their genomic array, which serves to illustrate how legal constraints can lead to a nonsensical situation despite the availability of novel technologies and scientific breakthroughs. As a result, it is clear that without models for facilitating access, the current system will likely collapse.

\section{Barriers to providing CGRA services}

\section{Costs and reimbursement rates}

At a systems level, the barriers to providing cancer genetics risk assessment services by trained professionals involve high costs and low reimbursement rates for these time-intensive services. This impedes the provision of adequate risk counseling, particularly for physicians outside of an academic setting. ${ }^{20-25}$ Findings from one study found that only one-third of the time needed to deliver genetic counseling services involves face-to-face patient care which may be billed. ${ }^{26}$ As a consequence, most genetic counseling programs cost more than the direct revenue they generate. ${ }^{27}$ However, when performing any cost-benefit calculation of genetic counseling services, "downstream revenue analysis" (which includes reimbursement from surveillance, prophylactic surgeries, or cancer treatments for individuals with inherited cancer predisposition) must be considered to fully illustrate the institutional value of these services. ${ }^{28}$ Furthermore, to maximize the efficiency of genetic counseling programs, administrative assistance is required for patient scheduling, filing, medical records requests, submission of insurance reimbursement claims and so on, to ensure maximum patient throughput by a genetic counselor.

\section{Licensing}

Another barrier to reimbursement is that genetic counselors are not allowed to bill directly for services in most states. However, the landscape continues to evolve as more states adopt licensure for genetic counselors, which may facilitate counselors' ability to bill for services. ${ }^{29}$ Specifically, 15 states have adopted rules that require genetic counselors to meet specific education, examination, and other standards before becoming licensed. ${ }^{29}$ Although the state laws vary, they do follow some common trends. For example, all 15 states provide title protection by making it illegal for a person to represent themselves as a genetic counselor. Without such title protection, anyone in that state can use the term genetic counselor. In addition to the 15 states that have laws on licensure, 17 states are either preparing to introduce bills on this matter or have bills pending so that the total number of states in which genetic counselors will be regulated is likely to rise in the future. Thus, a health care provider could unknowingly refer a patient to a genetic counselor who does not have graduate training in genetic counseling or even a basic level of proficiency. This places health care providers at risk for using these untrained individuals, and consumers at risk for not receiving adequate services. In some states, the penalties for violating the licensing laws for genetic counselors range from civil consequences such as fines or restraining orders to criminal consequences such as misdemeanors or felonies. However, it is important to note that most states have provisions that clarify that other health care professionals are not in violation of the law if they provide genetic counseling services within the scope of their licensing laws. In such a case, health care professionals still cannot present themselves with the title of genetic counselor.

Despite current inability for most genetic counselors to bill independently for services rendered, there is evidence to suggest that provision of genetic counseling through a trained genetics professional can lead to increased cost effectiveness. ${ }^{30}$ In fact, a large health insurance plan within the state of Michigan, PriorityHealth, requires genetic counseling by a trained genetics professional before genetic testing as a prerequisite to reimbursement for testing for the specific purpose of promoting cost effectiveness. ${ }^{31,32}$ Ultimately, public and private health care policy reform is needed to address the gap in insurance coverage for genetic counseling and genetic testing as a component of preventive care for patients, as well as to improve reimbursement relative to the time required for adequate risk counseling. There has been some policy 
movement in this area, but it has been limited. For example, under the Affordable Care Act, most insurance companies now have to cover genetic counseling on $B R C A$ for women who are at higher risk at no cost to the patient. ${ }^{33}$ These types of mandates are few and far between in the insurance realm.

\section{Limited workforce}

Finally, there is a recognized shortage of genetics professionals, especially in rural areas and certain states. ${ }^{34,35}$ National data indicates there are 1,500 medical geneticists and just over 2,000 genetic counselors in the United States, which translates into 1 genetics professional per 300,000 individuals in the population. Ultimately, expansion in access to genetics expertise will be a key component to realizing the benefits of genetics and genomics innovations.

\section{Risks associated with incomplete CGRA services}

There is data to suggest that many nongenetics professionals lack sufficient knowledge to provide adequate CGRA services. ${ }^{36-39}$ In fact, a number of recent publications have demonstrated the negative outcomes of undergoing genetic testing without adequate genetic counseling, such as inappropriate or incomplete testing and misinterpretation of test results by both patients and clinicians, inappropriate cancer screening or prevention recommendations, and possible psychological complications for the patient. ${ }^{38-42}$ There is a need to better understand the effectiveness of counseling at an academic center, which generally involves multidisciplinary care with the involvement of genetics professionals, compared with community programs. On the surface, the sharing of genetic test results may seem to be basic. However, when the intricacies are examined, the knowledge that is needed for delivering the results can become quite complex.

The delivery of positive results requires clinicians to be familiar with the latest management strategies available to the patient and with risk modifiers to be able to convey accurate cancer risk and management recommendations to the patient. Inheritance patterns must also be understood to help the patient inform at-risk relatives. The delivery of "true negative" results, where a patient is tested for a previously identified family mutation, may seem straightforward; however CGRA services entail comprehensive assessment of maternal and paternal inheritance. For example, a patient presented to our clinic for sitespecific testing for a previously identified $B R C A$ mutation coming from her mother's side of the family. During the CGRA session, she was determined to have a significant paternal family history of Lynch syndrome, and subsequent genetic testing identified a mutation in the $M L H 1$ gene. Another challenge is determining appropriate clinical management for patients who receive an "uninformative" negative result (ie, where a causative mutation has not been identified in the family, thus a "negative" result does not equate to no risk in families), particularly when a positive result was expected. Given that $90 \%$ of results are typically negative, this is a common scenario and requires providers to discuss the possibility of other genetic conditions, as appropriate. ${ }^{9,43}$ The identification of another genetic syndrome in a patient has direct implications for the medical management recommendations that are made to the patient. Finally, a result that includes a variant of unknown significance (VUS) brings an extra layer of complexity to CGRA sessions, because it is imperative for the clinician to gather additional information on the VUS and to interpret the result in the context of the family history. Furthermore, the reporting of VUS results is not standardized between different genetic testing laboratories, thus familiarity and understanding of 1 laboratory's classification does not translate into the same interpretation at another laboratory, which may have a notable impact on clinical utility. Clinicians must have an understanding of the methodology behind a VUS classification, know where to obtain more information about a VUS, and understand how to use the information to better guide the management of their patients. In fact, a $B R C A$ VUS result in a patient who was recently seen through our clinic was reported to have a $46: 1$ odds of being pathogenic. ${ }^{44}$ Thus, collection of this additional information had an impact on both the breast and ovarian cancer risk management decisions the patient made.

That being said, successful strategies for delivering comprehensive CGRA services include provision of these services in a multidisciplinary setting. This includes academiccommunity partnerships that focus on collaboration with nongenetics providers to offer genetic testing for hereditary cancers or inclusion of a genetics professional in the community setting as part of multidisciplinary patient care. ${ }^{9,43}$ These approaches can leverage expertise of genetics professionals while allowing patients to remain in their community and allow for better access to resources for long-term follow-up care.

Another consideration for nongenetics professionals who perform genetic testing is the duty to follow up with patients as newer tests emerge. Specifically, when genetic services are provided as a consultation service by genetics professionals, the patient is seen specifically for an evaluation and is generally not followed on an ongoing basis. In contrast, when genetic testing is performed by oncologists, gynecologists, or other primary care doctors in the community as part of ongoing care, it becomes the responsibility of the treating practitioner to follow-up with 
patients as new genetic testing is introduced from which the patient might benefit. Thus, lack of documented discussion about emerging tests as they become available may pose another liability risk faced by community-based practitioners who offer genetic testing in the context of ongoing medical care. ${ }^{45}$ In addition, health care professionals have been sued when they have failed to recommend a needed genetic test. ${ }^{46,47}$

Ultimately, advances in genomic medicine will lead to more and more patients with disorders with a recognizable genetic component that will require specific medical management. Thus, health care professionals who are not familiar with basic concepts of medical genetics put their patients at risk of not receiving the best available care and put themselves at risk of a malpractice suit. In fact, recent literature has suggested that physicians appear to be the most vulnerable group in terms of liability risks related to genetic technologies, and with the growth in the field of genetics, the number of lawsuits is expected to increase substantially. ${ }^{46,47}$

\section{Future directions}

There remains a paucity of opportunities for education and training in clinical cancer genetics, ${ }^{48}$ despite the priorities set forth by policy and leadership stakeholders that emphasize the need for cancer genetics education. ${ }^{49-57}$ In the setting of a limited trained professional workforce and limited education and training resources, it is a challenge to integrate genetic testing for inherited cancer predisposition into clinical care. As part of campaigns to increase awareness of hereditary breast and ovarian cancer and testing for the BRCA genes, Myriad, the company with the patent on these genes, has provided physician education and outreach in the community setting. However, there is much concern about whether a few hours of training by company employees with an inherent conflict of interest in selling test kits is either appropriate or adequate. ${ }^{49}$ Furthermore, it is important to recognize that events supported by educational grants from commercial companies often use members of their speaker's bureaus who convey a message consistent with the company's goals. As a result, these events have the potential for commercial bias. Ultimately, many well-meaning health care providers who have no training in CGRA are encouraged to order $B R C A$ testing with the help of a simple informational packet. Thus, BRCA testing is routinely performed by physicians who lack adequate knowledge of even basic genetic concepts, ${ }^{58-61}$ which represents a medical liability for them, while sales representatives are rewarded with commissions for the ordered test.

Targeting appropriate utilization of cancer genetics services has been a long-standing research focus at the Moffitt Cancer Center. We recently received a grant to develop an infrastructure (called the Inherited Cancer Research [ICARE] Initiative) to support research, education, and outreach initiatives focused on $B R C A$ genetic counseling and testing. The ICARE Initiative leverages a state mandate to reach the citizens of Florida and provide access to highquality cancer care. Moffit works with its partners (referred to as 'Affiliates') to offer clinical expertise and research trials found at an NCI-designated Comprehensive Cancer Center. In addition to our educational and outreach efforts, practitioners statewide refer high-risk patients to our research registry to provide the research link, which has in turn contributed to the tremendous growth of our registry since initiation of the grant in summer 2010. This provides unprecedented opportunities to understand cancer risk management practices and recommendations in $B R C A$ mutation carriers at the patient and practitioner level. These efforts will lead to information that can improve the delivery of cancer genetics services in the state of Florida and serve as a model for other states. Recognizing community-based needs, both at the patient and practitioner level, a nonprofit foundation, Inherited Cancer Coalition was formed, through which educational materials pertinent to genetics and genomics are under development.

In the end, it is important to recognize that genetics is qualitatively different from all other topics in medicine because it underlies all of pathophysiology. It is the fundamental science of health and disease ${ }^{61}$ and will increasingly influence the health care environment with continuing emerging advances in genetics and genomics. With the tremendous reductions in genotyping costs that now allow for simultaneous testing for multiple inherited conditions, we expect the genetic testing paradigm to shift away from testing for 1 condition at a time toward testing through multigene panels. That shift to multigene testing will add to the complexities of delivering genetics services and compound the existing problems. These advances will magnify the need for practitioners to have a required level of proficiency in genetics, with genetics professionals available for consultations and guidance.

\section{Acknowledgements}

This work was supported in part by a grant through Florida Biomedical (IBG09-34198). We thank Veronica Harville for administrative assistance.

\section{References}

1. Radford C. Understanding the Evolution of and Term "Genetic Counselor": is the Term Being Used Appropriately in Your Community. The Oncology Nurse. 2011;4(5):24-25.

2. Weitzel JN, Blazer KR, Macdonald DJ, Culver JO, Offit K. Genetics, genomics, and cancer risk assessment: state of the art and future directions in the era of personalized medicine. CA Cancer J Clin. [Epub ahead of print].

3. Fraser FC. Genetic counseling. Am J Hum Genet. 1974;26(5):636-661.

4. Bernhardt BA, Biesecker BB, Mastromarino CL. Goals, benefits, and outcomes of genetic counseling: client and genetic counselor assessment. Am J Med Genet. 2000;94(3):189-197. 
5. Shiloh S, Avdor O, Goodman RM. Satisfaction with genetic counseling: dimensions and measurement. Am J Med Genet. 1990; 37(4):522-529.

6. Pilnick A, Dingwall R. Research directions in genetic counselling: a review of the literature. Patient Educ Couns. 2001;44(2):95-105.

7. MacDonald DJ, Blazer KR, Weitzel JN. Extending comprehensive cancer center expertise in clinical cancer genetics and genomics to diverse communities: the power of partnership. J Natl Compr Canc Netw. 2010;8(5):615-624.

8. Zon RT, Goss E, Vogel VG, et al. American Society of Clinical Oncology policy statement: the role of the oncologist in cancer prevention and risk assessment. J Clin Oncol. 2009;27(6):986-993.

9. Geier LJ, Mulvey TM, Weitzel JN. Clinical cancer genetics remains a specialized area: how do I get there from here? ASCO 2009 Educational Book: Practice Management and Information Technology. http://meetinglibrary.asco.org/sites/meetinglibrary.asco.org/ files/Educational\%20Book/PDF\%20Files/2009/09edbk.practmgmt. 03.pdf. Accessed April 26, 2013

10. Evans JP. Health care in the age of genetic medicine. JAMA. 2007;298(22):2670-2672.

11. ACOG Practice Bulletin No. 103: Hereditary breast and ovarian cancer syndrome. Obstet Gynecol. 2009;113(4):957-966.

12. Bowen DJ, Battuello KM, Raats M. Marketing genetic tests: empowerment or snake oil? Health Educ Behav. 2005;32(5):676-685.

13. Vadaparampil ST, Wideroff L, Breen N, Trapido E. The impact of acculturation on awareness of genetic testing for increased cancer risk among Hispanics in the year 2000 National Health Interview Survey. Cancer Epidemiol Biomarkers Prev. 2006;15(4):618-623.

14. Hogarth S, Javitt G, Melzer D. The current landscape for directto-consumer genetic testing: legal, ethical, and policy issues. Annu Rev Genomics Hum Genet. 2008;9:161-182.

15. Javitt GH, Hudson K. Federal Neglect: Regulation of Genetic Testing. Issues in Science and Technology. 2006;22(3):59-66.

16. Horn EJ, Terry SF. Regulating genetic tests: issues that guide policy decisions. Genet Test Mol Biomarkers. 2012;16(1):1-2.

17. ACLU Challenges Patents on Breast Cancer Genes: BRCA [news release]. American Civil Liberties Union. Released May 12, 2009, updated May 15, 2009. http://www.aclu.org/free-speechwomens-rights/aclu-challenges-patents-breast-cancer-genes. Accessed June 22, 2012

18. Huys I, Matthijs G, Van Overwalle G. The fate and future of patents on human genes and genetic diagnostic methods. Nat Rev Genet. 2012;13(6):441-448.

19. Association for Molecular Pathology v. Myriad Genetics [news release]. American Civil Liberties Union. http://www.aclu.org/print/free-speechtechnology-and-liberty-womens-rights/association-molecularpathology-v-myriad-genetics. Released April 14, 2013. Accessed April 26, 2013.

20. DeMarco TA, Smith KL, Nusbaum RH, Peshkin BN, Schwartz MD, Isaacs C. Practical aspects of delivering hereditary cancer risk counseling. Semin Oncol. 2007;34(5):369-378.

21. Lawrence WF, Peshkin BN, Liang W, Isaacs C, Lerman C, Mandelblatt JS. Cost of genetic counseling and testing for BRCA1 and BRCA2 breast cancer susceptibility mutations. Cancer Epidemiol Biomarkers Prev. 2001;10(5):475-481.

22. Schwartz GF, Hughes KS, Lynch HT, et al. Proceedings of the international consensus conference on breast cancer risk, genetics, \& risk management, April, 2007. Breast J. 2009;15(1):4-16.

23. Hampel H, Sweet K, Westman JA, Offit K, Eng C. Referral for cancer genetics consultation: a review and compilation of risk assessment criteria. J Med Genet. 2004;41(2):81-91.

24. Weitzel JN. Genetic cancer risk assessment. Putting it all together. Cancer. 1999;86(11 Suppl):2483-2492.

25. Ganz PA, Kwan L, Somerfield MR, et al. The role of prevention in oncology practice: results from a 2004 survey of American Society of Clinical Oncology members. J Clin Oncol. 2006;24(18):2948-2957.

26. McPherson E, Zaleski C, Benishek K, et al. Clinical genetics provider real-time workflow study. Genet Med. 2008;10(9):699-706.
27. Tung N. Management of women with BRCA mutations: a 41year-old woman with a BRCA mutation and a recent history of breast cancer. JAMA. 2011;305(21):2211-2220.

28. Bernhardt BA, Tumpson JE, Pyeritz RE. The economics of clinical genetics services. IV. Financial impact of outpatient genetic services on an academic institution. Am J Hum Genet. 1992;50(1):84-91.

29. National Society of Genetic Counselors. States issuing licenses for genetic counselors. http://www.nsgc.org/Advocacy/StatesIssuingLicensesforGeneticCounselors/tabid/347/Defaultaspx. Updated September 18, 2012. Accessed June 15, 2012

30. Plon SE, Cooper HP, Parks B, et al. Genetic testing and cancer risk management recommendations by physicians for at-risk relatives. Genet Med. 2011;13(2):148-154.

31. PriorityHealth. Counseling before genetic testing. http://www. priorityhealth.com/member/health-wellness/health-help/geneticcounseling. Updated December 12, 2012. Accessed June 15, 2012.

32. Duquette D, Lewis K, McLosky J, Bach J. Using core public health functions to promote BRCA best practices among health plans. Public Health Genomics. 2012;15(2):92-97.

33. Preventive Services Covered Under the Affordable Care Act. Healthcare. gov Web site. http://www.healthcare.gov/news/factsheets/2010/07/ preventive-services-list.html. Updated September 27, 2012. Accessed June 22, 2012.

34. Acheson LS, Stange KC, Zyzanski S. Clinical genetics issues encountered by family physicians. Genet Med. 2005;7(7):501-508

35. Vig HS, Armstrong J, Egleston BL, et al. Cancer genetic risk assessment and referral patterns in primary care. Genet Test Mol Biomarkers. 2009;13(6):735-741.

36. O'Neill SC, Peshkin BN, Luta G, Abraham A, Walker LR, Tercyak KP. Primary care providers' willingness to recommend BRCA1/2 testing to adolescents. Fam Cancer. 2010;9(1):43-50.

37. Garber JE, Offit K. Hereditary cancer predisposition syndromes. J Clin Oncol. 2005;23(2):276-292.

38. Brierley KL, Blouch E, Cogswell W, et al. Adverse events in cancer genetic testing: medical, ethical, legal, and financial implications. Cancer J. 2012;18(4):303-309.

39. Brierley KL, Campfield D, Ducaine W, et al. Errors in delivery of cancer genetics services: implications for practice. Conn Med. 2010;74(7):413-423

40. Robson ME, Storm CD, Weitzel J, Wollins DS, Offit K. American Society of Clinical Oncology policy statement update: genetic and genomic testing for cancer susceptibility. J Clin Oncol. 2010;28(5):893901.

41. Esserman L, Kaklamani V. Lessons learned from genetic testing. JAMA. 2010;304(9):1011-1012.

42. Caleshu C, Day S, Rehm HL, Baxter S. Use and interpretation of genetic tests in cardiovascular genetics. Heart. 2010;96(20):1669-1675.

43. Cohen SA, McIlvried D, Schnieders J. A Collaborative Approach to Genetic Testing: A Community Hospital's Experience. J Genet Couns. 2009;18(6):530-533.

44. Easton DF, Deffenbaugh AM, Pruss D, et al. A systematic genetic assessment of 1,433 sequence variants of unknown clinical significance in the BRCA1 and BRCA2 breast cancer-predisposition genes. Am J Hum Genet. 2007;81(5):873-883.

45. Integrating genetic risk assessment into practice. J Onc Prac. 2008; 4(5):214-219

46. Lindor RA, Marchant GE. A review of medical malpractice claims related to clinical genetic testing [ASCO abstract 6073]. J Clin Onc. 2011;29(suppl)

47. Marchant GE, Campos-Outcalt DE, Lindor RA. Physician liability: the next big thing for personalized medicine? Personalized Medicine. 2011;8(4):457-467.

48. (ASCO) ASoCO. Cancer Genetics and Cancer Predisposition Testing. 2nd ed. Alexandria, VA: American Society of Clinical Oncology Publishing; 2004

49. Daly MB, Axilbund JE, Buys S, et al. Genetic/familial high-risk assessment: breast and ovarian. J Natl Compr Canc Netw. 2010; $8: 562-594$ 
50. Calzone KA, Jenkins J, Masny A. Core competencies in cancer genetics for advanced practice oncology nurses. Oncol Nurs Forum. 2002;29:1327-1333.

51. Genetic testing in adoption. The American Society of Human Genetics Social Issues Committee and The American College of Medical Genetics Social, Ethical, and Legal Issues Committee. Am J Hum Genet. 2000;66:761-767.

52. Kolb SE, Aguilar MC, Dinenberg M, Kaye CI. Genetics education for primary care providers in community health settings. $J$ Community Health. 1999;24:45-59.

53. Korf BR. Medical education in the 'postgenomic era.' Postgrad Med. 2000;108:15-18.

54. Peterson SK, Rieger PT, Marani SK, deMoor C, Gritz ER. Oncology nurses' knowledge, practice, and educational needs regarding cancer genetics. Am J Med Genet. 2001;98:3-12.

55. Reynolds PP, Benkendorf JL. Genes and generalists: why we need professionals with added competencies. West J Med. 1999;171: 375-379.

56. Schwartz MD, Valdimarsdottir HB, DeMarco TA, et al. Randomized trial of a decision aid for BRCA1/BRCA2 mutation carriers: impact on measures of decision making and satisfaction. Health Psychol. 2009;28:11-19.

57. Giardiello FM, Brensinger JD, Petersen GM, et al. The use and interpretation of commercial APC gene testing for familial adenomatous polyposis. N Engl J Med. 1997;336:823-827.

58. Wilkins-Haug L, Erickson K, Hill L, Power M, Holzman GB, Schulkin J. Obstetrician-gynecologists' opinions and attitudes on the role of genetics in women's health. $J$ Womens Health Gend Based Med. 2000;9:873-879.

59. Baars MJ, Henneman L, Ten Kate LP. Deficiency of knowledge of genetics and genetic tests among general practitioners, gynecologists, and pediatricians: a global problem. Genet Med. 2005;7: 605-610.

60. Wideroff L, Vadaparampil ST, Greene MH, Taplin S, Olson L, Freedman AN. Hereditary breast/ovarian and colorectal cancer genetics knowledge in a national sample of US physicians. $J$ Med Genet. 2005;42:749-755.

61. Grosse SD, Khoury MJ. What is the clinical utility of genetic testing? Genet Med. 2006;8:448-450. 